\title{
Experimental and Analytical Study on Local Buckling Behavior of the Concrete-filled Thin-walled Welded Steel Columns
}

\author{
Deividas Martinavičius ${ }^{1 *}$, Mindaugas Augonis , Mário Rui Tiago Arruda² \\ 1 Civil Engineering and Architecture Competence Centre, Faculty of Civil Engineering and Architecture, Kaunas University of Technology, \\ Studentu st. 48, Kaunas, Lithuania \\ ${ }^{2}$ Civil Engineering Research and Innovation for Sustainability, Instituto Superior Técnico, University of Lisbon, Av. Rovisco Pais 1 , \\ Lisbon, Portugal \\ * Corresponding author, e-mail: deividas.martinavicius@ktu.edu
}

Received: 06 February 2020, Accepted: 27 May 2020, Published online: 13 July 2020

\begin{abstract}
This paper presents an experimental investigation of the concrete filled thin-walled welded steel tubes. Square and rectangular columns are tested with and without the bond between the steel profile and concrete. In order to remove the bond in the latter columns a polyethylene (PE) film is placed inside of the steel profiles. Experimental results are verified via the finite element analysis and compared to the results obtained using the analytical calculation methods. The significance of the steel-concrete bond is evaluated, referring to the differences of the critical loads, ultimate loads and effective cross-sectional areas of the columns with and without the PE film inside and the differences are found to be considerable. It is found that the columns without the film had an up to $47 \%$ higher effective cross-sectional area to full cross-sectional area ratio. The average reduction of the effective cross-sectional area of the column having a poor bond is found to be $12 \%$. It is also found that the resistance is often overestimated when using the analytical formulas, especially for the columns with the PE film inside.
\end{abstract}

Keywords

steel-concrete columns, local buckling, effective width, steel-concrete bond, critical stress

\section{Introduction}

Steel-concrete structures are often used when a fast construction is required. This kind of structures also have a high fire resistance compared to the regular steel structures and are becoming very popular in the modern construction. The steel-concrete structures usually have a smaller cross-section than the conventional reinforced concrete structures. However, the thick and compact steel profiles are usually avoided because of their high price. Hence, it may be more economical to design slender cross-sections. In this case, the elements of the cross-section have a high width-to-thickness ratio and are classified as slender class 4 elements acc. to Eurocode 3 [1].

The conventional design approach for the slender cross-sections is to calculate the effective area. It is also adopted by the Eurocode 3 [2]. However, the design code for the composite structures Eurocode 4 [3] does not have the specific rules to evaluate the effective area, as it references Eurocode $3[1,2]$. Thus, this type of design may not be economical. The concrete infill increases the critical buckling load, as the steel plate is not able to buckle towards the inside of the profile. The buckling factor $k$ values equal to 9.33 [4], 10.3 [5], 10.67 [6] and 9.81 [7] were reported for the steel-concrete cross-sections, while the steel elements have a significantly lower value equal to 4.0 [6].

Different authors have made a significant research in the field of local buckling of the steel-concrete columns. The limit width-to-thickness ratio value when the local buckling can be disregarded is specified as $52 \varepsilon$ in the Eurocode 4 [3]. However, Song et al. [8] have proposed to assume this value as $38 \varepsilon$. Uy $[9,10]$ has tested a large amount of composite steel-concrete columns and presented a numerical method to predict the resistance of this kind of structures. Liang et al. [11] have proposed the expressions for calculating the critical buckling stress, ultimate stress and effective width of the plates under pure compression or eccentric compression in the steel-concrete columns. 
Various authors have also made a significant research regarding the confinement in the steel-concrete composite columns [12, 13]. Hu et al. [12] have found that there is no significant confinement for the rectangular sections with the $b / t$ ratio less than 29.2. Furthermore, Han et al. [13] carried out a large experimental campaign and proposed a simplified model to calculate the resistance of the composite square steel-concrete columns taking into account the confinement. The similar calculation model for the composite beams was created subsequently [14].

The purpose of this research is to evaluate the significance of the steel-concrete bond and assess the available analytical methods used to calculate the critical and ultimate loads of the composite steel-concrete columns. To achieve this goal, steel-concrete columns are tested under compression. In the literature reviewed, there was no information about the effect of the bond between the steel and concrete on the strength of the composite steelconcrete columns. The bond between the steel and concrete may be poor because of the concrete shrinkage or the poor compaction. Therefore, it is very important evaluate the significance of this factor on the resistance of the composite steel-concrete columns.

\section{Experimental program}

The experimental campaign was carried out to obtain the influence of the different width-to-thickness ratios and bond for the resistance of the steel-concrete columns. The experimental procedure is described in detail.

\subsection{Materials and specimens}

Sixteen columns were tested during the experimental program. Thirty $100 \times 100 \times 100$ concrete cubes were tested [15] to obtain the compressive strength of the concrete. Three specimens were formed for every batch of the concrete.
Ten prisms $100 \times 100 \times 300$ were tested [16] to obtain the Young's modulus of the concrete. The results and the corresponding standard deviations of the material properties are presented in the Table 1, where $f_{c 1}, f_{c 2}, f_{c 3}$ are the compressive strengths of the separate cubes, $f_{c, a v g}$ is an average compressive strength of the concrete specimens from the same batch and $E_{c}$ is the Young's modulus.

Five "bone" shaped steel specimens were tested [17] to obtain the yield and ultimate strength of the steel. The results are presented in the Table 2, where $f_{y}$ and $f_{u}$ are the yield strength and ultimate strength of the steel specimens, respectively.

The columns consisted of the separate plates that were fillet welded in the edges. Every column had eight stiffeners at the top and eight at the bottom, with the purpose to avoid the "elephant foot" buckling at the significantly lower load [10]. The dimensions, width-to-thickness ratios and material properties of the columns are presented in the Table 3, where $B$ and $H$ are the outer width and height of the column profile, $b$ and $h$ are the inner width and height of the profile, $t$ is the thickness of the steel profile, $L$ is the length of the column and $f_{y, a v g}$ is the average yield strength of the steel. First number of the column marking is the number of the cross-section series. Letter "W" refers to the thin PE film placed inside of the steel profile. The purpose of this film was to remove the cohesion between the steel and concrete. Letters "WO" refer to the profiles without the PE film inside. The principal drawing and the view of the hardened composite column is presented in the Fig. 1.

\subsection{Fabrication and casting}

The columns were initially tack welded and internal bracing was provided. The columns were then welded with the longitudinal fillet welds and internal bracing was removed. The concrete mix was poured into the columns

Table 1 Material properties of the concrete

\begin{tabular}{|c|c|c|c|c|c|}
\hline Column specimen group & $f_{c 1}(\mathrm{MPa})$ & $f_{c 2}(\mathrm{MPa})$ & $f_{c 3}(\mathrm{MPa})$ & $f_{c, a v g}(\mathrm{MPa})$ & $E_{c}(\mathrm{GPa})$ \\
\hline $1-\mathrm{WO}$ & 31.06 & 29.21 & 29.65 & $29.97 \pm 0.97$ & 32.623 \\
\hline $1-\mathrm{W}$ & 32.77 & 30.35 & 32.33 & $31.82 \pm 1.29$ & 34.423 \\
\hline 2-WO & 26.98 & 24.19 & 29.19 & $26.79 \pm 2.51$ & 32.176 \\
\hline $2-W$ & 27.36 & 25.07 & 25.35 & $25.93 \pm 1.25$ & 31.469 \\
\hline 3-W, 3.1-WO & 33.54 & 31.51 & 31.26 & $32.10 \pm 1.25$ & 32.204 \\
\hline $4-W$ & 29.18 & 29.23 & 32.83 & $30.41 \pm 2.10$ & 30.597 \\
\hline 3.2-WO, 4-WO & 36.22 & 30.17 & 34.39 & $33.59 \pm 3.10$ & 32.794 \\
\hline 5-W, 5-WO & 35.45 & 34.78 & 35.17 & $35.13 \pm 0.34$ & 34.074 \\
\hline $6-\mathrm{W}$ & 34.71 & 32.15 & 33.85 & $33.57 \pm 1.30$ & 34.078 \\
\hline 7-W, 7-WO, 8-W, 8-WO & 30.43 & 30.84 & 33.71 & $31.66 \pm 1.79$ & 30.474 \\
\hline Stand. deviation & & & & & \pm 1.404 \\
\hline
\end{tabular}


Table 2 Material properties of the steel

\begin{tabular}{lcc}
\hline Steel specimen & $f_{y}(\mathrm{MPa})$ & $f_{u}(\mathrm{MPa})$ \\
\hline SS-1 & 372.92 & 491.94 \\
SS-2 & 373.40 & 476.68 \\
SS-3 & 374.35 & 479.49 \\
SS-4 & 367.84 & 476.68 \\
SS-5 & 365.73 & 483.11 \\
Average strength & $370.85 \pm 3.82$ & $481.58 \pm 6.37$ \\
\hline
\end{tabular}

and consolidated using the internal electric concrete vibrator. The specimens were covered with the polyethylene film to simulate the conditions in the building site and left to cure for 28 days. Some hardened surfaces of the columns were polished and some other surfaces had a mortar layer applied to make it level with the steel edges.

\subsection{Test setup and procedure}

Hydraulic 500 tons press was used to load the columns. The experimental scheme and experimental setup is presented in Fig. 2.

Every column was centered and three strain gauges (S1, S2, S3) were glued on one side. It was noticed during the pre-testing that the usual local buckling areas were the midheight of the column or approximately $5 \mathrm{~cm}$ away from the end stiffeners. Thus, the strain gauges were glued in those areas. Two electronic LVDT transducers (T1 and T2) were used to measure the movement of the base of the press and evaluate the axial shortening of the columns. Two more transducers (T3 and T4) were used to measure the lateral

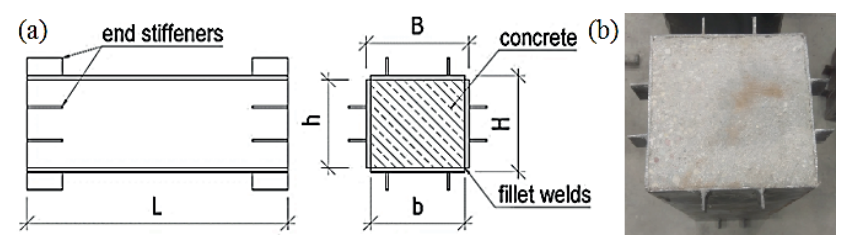

Fig. 1 Principal drawing (a) and view of the composite column (b)

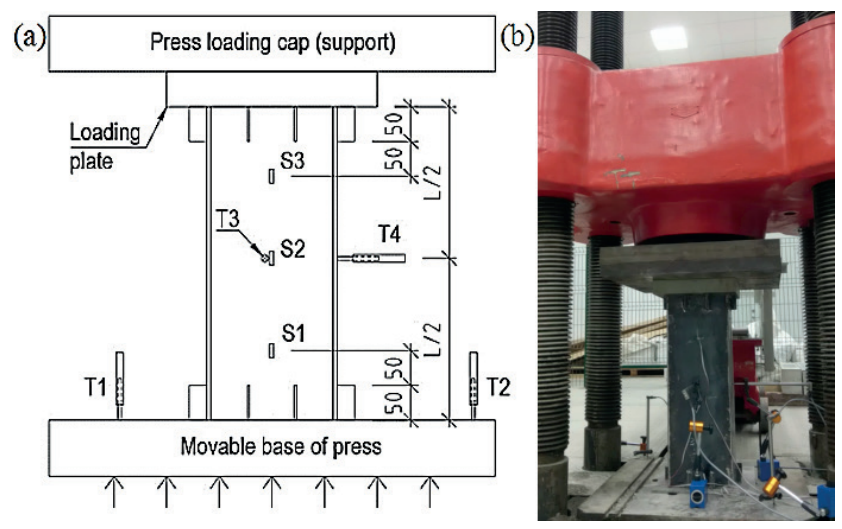

Fig. 2 Experimental scheme (a) and experimental setup (b)

displacement of the webs. Electronic equipment was used to write and save the results. The load was increased at the rate of $10 \mathrm{kN} / \mathrm{s}$. The loading was stopped when the specimens lost at least $10 \%$ of the maximum load.

\section{Analytical calculation methodologies}

\subsection{Critical stress}

Elastic critical buckling stress of the perfect steel plate under uniform edge compression can be calculated using the following expression [18]:

Table 3 Column specimens and material properties

\begin{tabular}{|c|c|c|c|c|c|c|c|c|}
\hline Column specimen & $B(\mathrm{~mm})$ & $H(\mathrm{~mm})$ & $t(\mathrm{~mm})$ & $b / t$ & $h / t$ & $L(\mathrm{~mm})$ & $f_{c, a v g}(\mathrm{MPa})$ & $f_{y, \text { avg }}(\mathrm{MPa})$ \\
\hline $1-\mathrm{WO}$ & 244.3 & 184.8 & 3.12 & 76.4 & 57.3 & 719.3 & 29.97 & 370.85 \\
\hline $1-W$ & 244.8 & 184.8 & 3.05 & 78.2 & 58.6 & 718.5 & 31.82 & 370.85 \\
\hline 2-WO & 243.0 & 243.5 & 3.09 & 76.7 & 76.9 & 718.0 & 26.79 & 370.85 \\
\hline $2-W$ & 243.8 & 243.5 & 3.14 & 75.8 & 75.7 & 719.0 & 25.93 & 370.85 \\
\hline $3-W$ & 204.0 & 204.0 & 3.09 & 64.1 & 64.1 & 598.8 & 32.10 & 370.85 \\
\hline 3.1-WO & 204.0 & 204.0 & 3.02 & 65.7 & 65.7 & 599.5 & 32.10 & 370.85 \\
\hline 3.2-WO & 205.0 & 205.5 & 3.10 & 64.2 & 64.4 & 598.3 & 33.59 & 370.85 \\
\hline $4-W$ & 185.0 & 123.3 & 3.15 & 56.7 & 37.1 & 539.0 & 30.41 & 370.85 \\
\hline 4-WO & 184.8 & 125.3 & 3.10 & 57.5 & 38.4 & 537.3 & 33.59 & 370.85 \\
\hline $5-W$ & 223.8 & 163.5 & 3.07 & 70.8 & 51.2 & 659.3 & 35.13 & 370.85 \\
\hline $5-\mathrm{WO}$ & 224.8 & 164.5 & 3.07 & 71.3 & 51.6 & 659.0 & 35.13 & 370.85 \\
\hline $6-W$ & 184.3 & 185.0 & 2.98 & 59.9 & 60.2 & 539.5 & 33.57 & 370.85 \\
\hline $7-W$ & 165.0 & 165.0 & 3.07 & 51.7 & 51.7 & 479.0 & 31.66 & 370.85 \\
\hline 7-WO & 164.8 & 165.3 & 3.08 & 51.5 & 51.7 & 479.0 & 31.66 & 370.85 \\
\hline $8-W$ & 145.0 & 145.0 & 3.09 & 44.9 & 44.9 & 419.0 & 31.66 & 370.85 \\
\hline 8-WO & 145.5 & 145.8 & 3.06 & 45.5 & 45.6 & 419.0 & 31.66 & 370.85 \\
\hline
\end{tabular}




$$
\sigma_{c r}=\frac{k \cdot \pi^{2} \cdot E_{s}}{12\left(1-v^{2}\right) \cdot\left(\frac{b}{t}\right)^{2}},
$$

where: $k$ - local buckling coefficient, assumed as 9.81 [19]; $E_{s}$ - elastic modulus of steel; $v$ - Poisson's ratio of steel.

Expression of Liang et al. [11] was used to calculate the critical stress of the imperfect steel plate:

$\sigma_{1 c, L}=f_{y}\left(a_{1}+a_{2}\left(\frac{b}{t}\right)+a_{3}\left(\frac{b}{t}\right)^{2}+a_{4}\left(\frac{b}{t}\right)^{3}\right)$,

where: $a_{1}=1, a_{2}=0.5507, a_{3}=9.869 \cdot 10^{-5}$ and $a_{4}=1.198 \cdot 10^{-7}$ are the constant coefficients.

\subsection{Effective width and ultimate stress}

Equations of Liang et al. [11] were used to obtain the effective widths of the steel plates. For the case when $\sigma_{1 c, L}<f_{y}$, the effective width is expressed as:

$b_{\text {eff }, L}=b\left(0.675 \cdot\left(\frac{\sigma_{c r}}{f_{y}}\right)^{\frac{1}{3}}\right)$.

Otherwise, when $\sigma_{1 c, L}>f_{y}$ :

$b_{\text {eff }, L}=b\left(0.915 \cdot\left(\frac{\sigma_{c r}}{\sigma_{c r}+f_{y}}\right)^{\frac{1}{3}}\right)$.

Bradford et al. [20] has modified the effective width models for hot-rolled and fabricated sections to take into account residual stresses and initial imperfections:

$\frac{b_{e f f, B r}}{b}=\alpha \sqrt{\frac{\sigma_{c r}}{f_{y}}}$,

where: $\alpha$ - parameter used to account for the residual stresses and initial geometric imperfections, assumed as 0.6 for the heavily welded plates [20].

Expression of Ge and Usami [21] was used to calculate the ultimate stress of the composite column:

$\sigma_{b}=f_{y}\left(\frac{1.2}{R}-\frac{0.3}{R^{2}}\right) \leq f_{y}$,

where: $R$ is the width-to-thickness ratio parameter.

$R=\frac{b}{t} \sqrt{\frac{12\left(1-v^{2}\right)}{\pi^{2} k}} \cdot \sqrt{\frac{f_{y}}{E_{s}}}$

The ultimate stress of the plate can then be recalculated to the effective area with a yield stress.

\section{Results and discussion}

\subsection{Experimental results}

The typical buckling areas are shown in the Fig. 3. The experimental load-axial shortening curves are presented in Fig. 4 to Fig. 7. Curves of the columns of the similar cross section (type "W" and "WO") are presented in the same figure and marked with the same color.
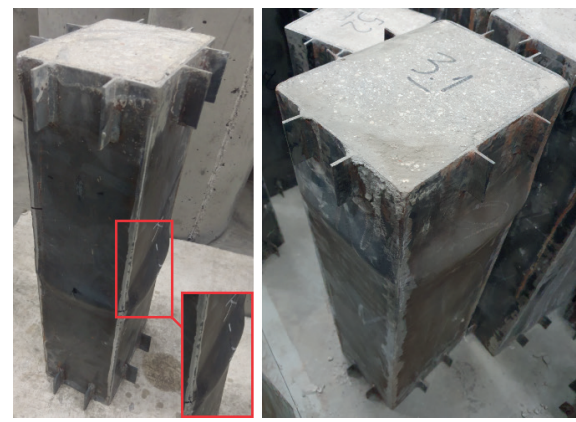

Fig. 3 Local buckling of the columns

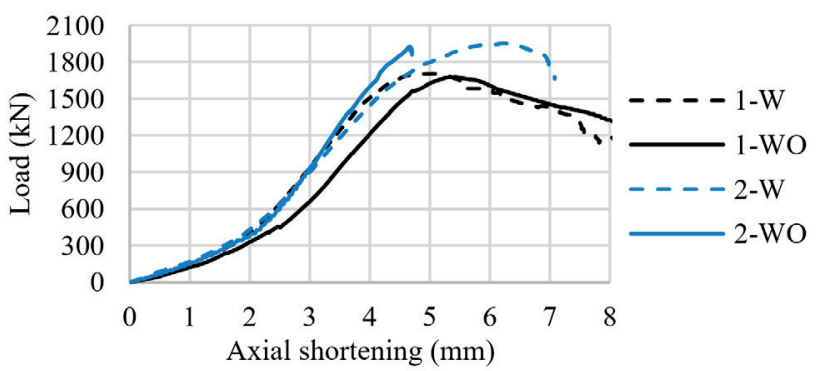

Fig. 4 Load-axial shortening curves of the columns 1-W, 1-WO, 2-W and 2-WO

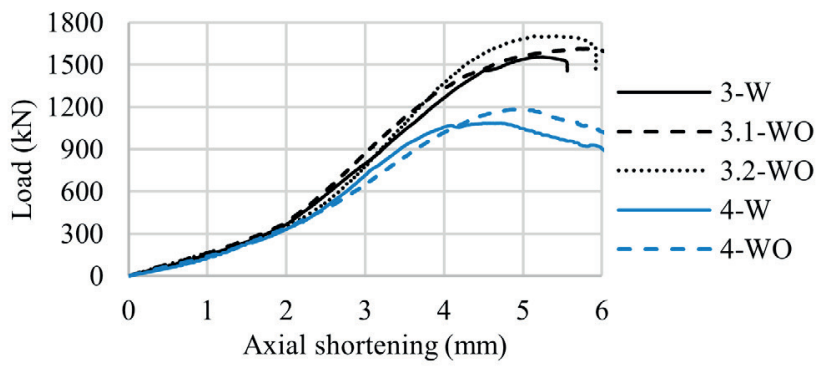

Fig. 5 Load-axial shortening curves of the columns 3-W, 3.1-WO, 3.2WO, 4-W and 4-WO

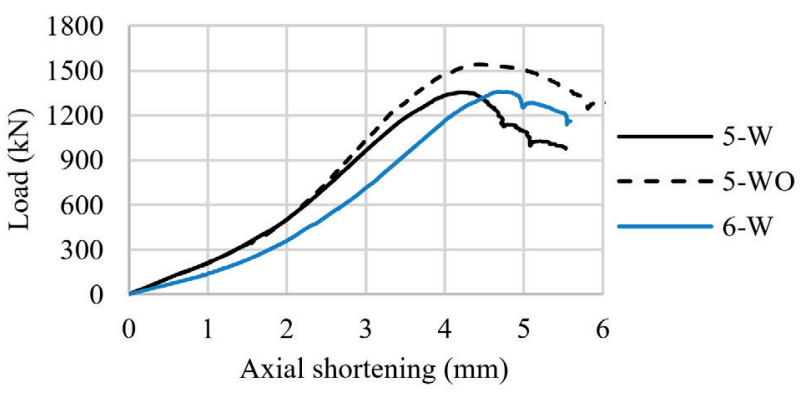

Fig. 6 Load-axial shortening curves of the columns 5-W, 5-WO and 6-W 


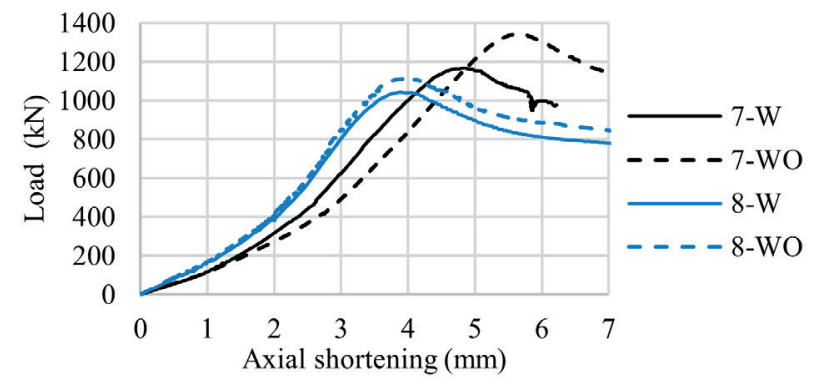

Fig. 7 Load-axial shortening curves of the columns 7-W, 7-WO, 8-W and $8-\mathrm{WO}$

It was noticed that the shortening of the columns was significantly higher than expected. The initial stiffness could be lower, as the column surfaces may have to adjust to the loading plates. However, observing the area where the load-axial shortening curve is normalized and close to linear, the experimental stiffness is still several times lower than the corresponding theoretical elastic stiffness. This type of difference between the experimental and theoretical stiffness was also reported in the researches of other authors [12, 22, 23, 24] and could be due to: small gaps between the hydraulic press, loading plates and loading surfaces; small eccentricity of the load and outof-straightness of the column; micro cracks caused by the restrained shrinkage of the concrete core provided by the friction of the concrete core and steel profile [24]. The stiffness could also be significantly influenced by the roughness of the column surfaces. Even though the surfaces were polished, the ideal smoothness is difficult to achieve. If there was at least a minor protrusion of the concrete above the steel edges on the loading surfaces, the concrete would be loaded first. Once the steel profile is loaded, the concrete could have already started behaving nonlinearly. In this case, the column would never reach the predicted elastic stiffness. Furthermore, due to the limitations of the measuring equipment, the displacement of only the bottom support of the press was measured. Thus, the settlement of the top support led to the increased axial shortening. However, it had no impact on the ultimate strength results.

Load-web displacement curves of the two webs of every column were obtained. The typical curve (column 3.2 WO) is presented in the Fig. 8. It can be seen in this graph that the local buckling has started (critical load $N_{1 c, e x}$ ) in the interval of $700-900 \mathrm{kN}$. It could be associated with the onset of the nonlinearity in the curve. However, the nonlinear dependency between the load and web displacement could also possibly start due to the onset of the nonlinear

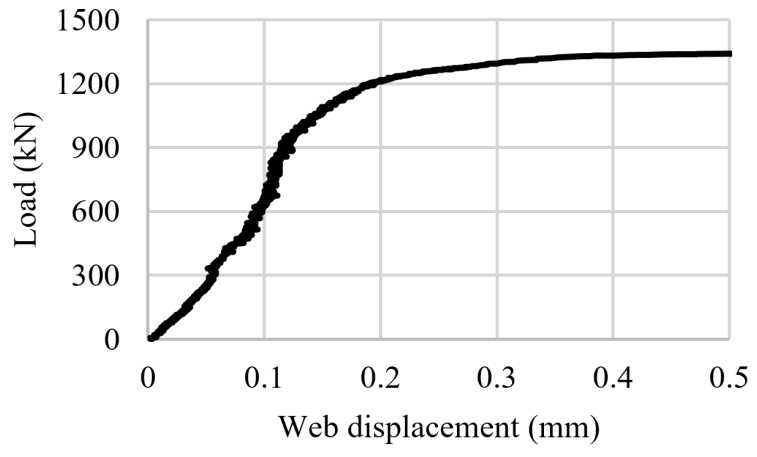

Fig. 8 Load-web displacement curve of the column 3.2-WO

deformations of the concrete. Thus, the load-web displacement curves have to be analyzed together with the loadstrain curves.

The results of the strain gauges of the column 3.2-WO are presented in the Fig. 9. The onset of the local buckling can be assumed the part of the strain gauge SG1 curve where the compressive strains stopped propagating, which corresponds to the critical load $N_{1 c, e x}$ of $700 \mathrm{kN}$. The strain value, corresponding to the critical load $N_{1 c, e x}$ is then multiplied by the Young's modulus of the steel to obtain the experimental critical stress $\sigma_{1 c, e x}$.

Experimental results are presented in the Table 4, where $N_{1 c, e x}$ is an experimental critical load, $N_{u, e x}$ - an experimental ultimate load, $A_{\text {eff }}$ - an effective cross-sectional area of the steel profile in the composite column, $A_{s}-$ a full cross-sectional area of the steel profile and $f_{u, e x}$ is an experimental average ultimate stress of the slender steel profile in the composite column, calculated using Eq. (8):

$f_{u, e x}=\frac{N_{u, e x}-b \cdot h \cdot f_{c m}}{A_{s}}$,

where: $f_{c m}$ is an average cylinder strength of the concrete, calculated from Eq. 9 [24]:

$f_{c m}=\left(0.76+0.2 \log _{10} \frac{f_{c, a v g}}{19.6}\right) f_{c, a v g}$.

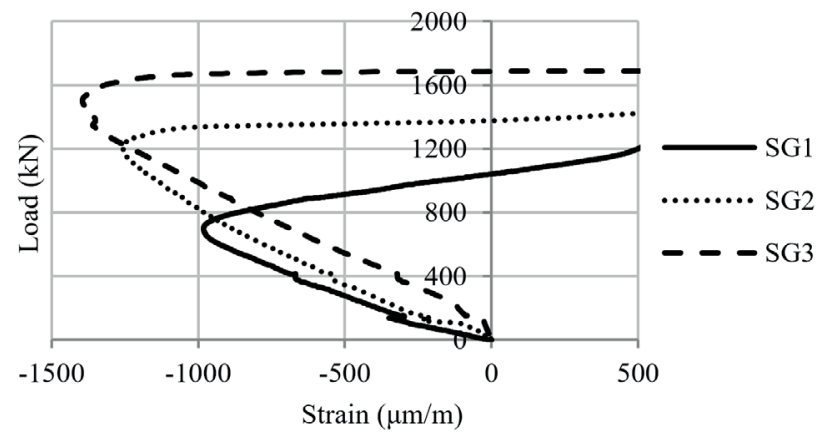

Fig. 9 Load-strain curves of the column 3.2-WO 
Table 4 Local and post-local buckling results of the columns

\begin{tabular}{lccccccccc}
\hline Column specimen & $b / t$ & $h / t$ & $N_{1 c, e x}$ & $N_{u, e x}$ & $\sigma_{1 c e x}$ & $f_{u, e x}$ & $\sigma_{1 c, e x} / f_{y}$ & $f_{u, e x} / f_{y}$ & $A_{e f f} / A_{s}$ \\
\hline 1-W & 78.2 & 58.6 & 1350.0 & 1706.6 & 157.5 & 242.3 & 0.42 & 0.65 & 0.65 \\
1-WO & 76.4 & 57.3 & 975.0 & 1682.6 & 149.1 & 253.9 & 0.40 & 0.68 & 0.68 \\
2-W & 75.8 & 75.7 & 1400.0 & 1957.0 & 165.9 & 263.1 & 0.45 & 0.71 & 0.71 \\
2-WO & 76.7 & 76.9 & 1750.0 & 1930.5 & 228.3 & 246.4 & 0.62 & 0.66 & 0.66 \\
3-W & 64.1 & 64.1 & 600.0 & 1554.9 & 127.1 & 223.5 & 0.34 & 0.60 & 0.60 \\
3.1-WO & 65.7 & 65.7 & 600.0 & 1612.1 & 130.0 & 251.7 & 0.35 & 0.68 & 0.68 \\
3.2-WO & 64.2 & 64.4 & 700.0 & 1701.9 & 204.8 & 256.5 & 0.55 & 0.69 & 0.69 \\
4-W & 56.7 & 37.1 & 900.0 & 1085.3 & 240.2 & 306.2 & 0.65 & 0.83 & 0.83 \\
4-WO & 57.5 & 38.4 & 800.0 & 1184.2 & 192.2 & 328.5 & 0.52 & 0.89 & 0.89 \\
5-W & 70.8 & 51.2 & 750.0 & 1352.7 & 154.4 & 168.1 & 0.42 & 0.45 & 0.45 \\
5-WO & 71.3 & 51.6 & 1300.0 & 1543.7 & 210.0 & 244.8 & 0.57 & 0.66 & 0.66 \\
6-W & 59.9 & 60.2 & 950.0 & 1358.4 & 85.3 & 233.7 & 0.23 & 0.63 & 0.63 \\
7-W & 51.7 & 51.7 & 1025.0 & 1167.2 & 204.8 & 268.1 & 0.55 & 0.72 & 0.72 \\
7-WO & 51.5 & 51.7 & 1100.0 & 1343.2 & 228.9 & 356.4 & 0.62 & 0.96 & 0.96 \\
8-W & 44.9 & 44.9 & 900.0 & 1043.4 & 263.3 & 320.1 & 0.71 & 0.86 & 0.86 \\
8-WO & 45.5 & 45.6 & 1000.0 & 1112.0 & 207.9 & 358.6 & 0.56 & 0.97 & 0.97 \\
\hline
\end{tabular}

The results of the critical stresses had a high scatter. In some cases, W type columns had a higher critical stress than the corresponding WO type columns. The possible reasons are discussed in the following section. The effective area factors $A_{\text {eff }} / A_{s}$ were in most cases higher for the WO type columns. The highest difference of the factor $A_{\text {eff }} A_{s}$ was $+47 \%$ comparing WO type columns to W type columns. Only one $\mathrm{W}$ type column (series 2 ) had a higher $A_{\text {eff }} / A_{s}$ factor than the corresponding WO type column. However, the difference was only $9 \%$ and it could be partly due to the uncertainty of the concrete strength or the excessive initial imperfections for those specific columns of the Series 2.

\subsection{Comparison of experimental and analytical results}

Comparison of the experimental and analytical results is presented in Table 5. $N_{1 c \text {, Liang }}$ is the predicted critical load, assuming the critical stress calculated from Eq. (2). $N_{u, \text { Liang }}$ is the predicted ultimate load, assuming the effective widths calculated from Eq. (3) and Eq. (4). $N_{u, B r}$ is the ultimate load, assuming the effective widths calculated from Eq. (5). $N_{u, G e}$ is the ultimate load, assuming the ultimate stress of the steel profile obtained from Eq. (6) and recalculating this stress to the effective cross-sectional area with a yield stress. $N_{1 c \text {,Liang }}$ values are calculated assuming the critical stress of the steel and the corresponding strain and stress values of the concrete. $N_{u, L i a n g}, N_{u, B r}$ and $N_{u, G e}$ values are calculated assuming the effective cross-sectional areas, yield strength of the steel and the average cylinder compressive strength of the concrete (Eq. 9).
The variation of the factor $N_{1 c, e x} / N_{1 c, \text { Liang }}$ for the critical loads was large (from 0.49 to 1.19). Wherever possible, it is advisable to use more strain gauges. Because of the possible eccentricities, the strains on the different sides may develop unevenly. Furthermore, the buckling wave starts to form at the different height of the column, which makes it difficult to capture with the strain gauges. The critical loads are also sensitive to the initial geometrical imperfections and residual stresses. Those reasons could lead to the inaccuracy of the critical stress measurement of some columns, where WO type column had a lower critical load than the corresponding W type column. The $N_{u, e x} / N_{u, \text { Liang }}, N_{u, e x} / N_{B r}$, $N_{u, e x} / N_{G e}$ values were higher for the "WO" type columns in most cases. The only exception was the series 2 columns. The possible reasons were described in the Section 4.1. Nevertheless, the ultimate strength of the type "WO" columns was usually not overpredicted or overpredicted less. The best agreement to the experimental ultimate loads was obtained using the method of Liang et al. [11]. The extreme values varied from the underprediction of $10 \%$ to overprediction of $14 \%$. The difference of the $N_{u, e x} / N_{u, \text { Liang }}$ values for the W and WO type of columns could be explained by the idea that the cohesion helps to stabilize the steel profile areas that are closer to the corners, which increases the effective cross sectional area. It is likely that the cohesion between the steel and concrete in the middle of the steel panels undergoing buckling is already lost when the column has reached the ultimate load, but some cohesion may still remain in the corners of the column. 
Table 5 Comparison of the experimental and analytical local and post-local buckling results

\begin{tabular}{|c|c|c|c|c|c|c|c|c|c|c|}
\hline Column specimen & $\begin{array}{l}N_{1 c, e x} \\
(\mathrm{kN})\end{array}$ & $\begin{array}{l}N_{u, e x} \\
(\mathrm{kN})\end{array}$ & $\begin{array}{c}N_{\text {lc,Liang }} \\
(\mathrm{kN})\end{array}$ & $\begin{array}{c}N_{u, \text { Liang }} \\
(\mathrm{kN})\end{array}$ & $\begin{array}{l}N_{u, B r} \\
(\mathrm{kN})\end{array}$ & $\begin{array}{l}N_{u, G e} \\
(\mathrm{kN})\end{array}$ & $N_{1 c, e x} / N_{1 c, \text { Liang }}$ & $N_{u, e x} / N_{u, \text { Liang }}$ & $N_{u, e x} / N_{u, B r}$ & $N_{u, e x} / N_{u, G e}$ \\
\hline $1-\mathrm{W}$ & 1350.0 & 1706.6 & 1136.1 & 1730.7 & 1700.7 & 1950.2 & 1.19 & 0.99 & 1.00 & 0.88 \\
\hline 1 -WO & 975.0 & 1682.6 & 1132.9 & 1684.4 & 1660.9 & 1908.6 & 0.86 & 1.00 & 1.01 & 0.88 \\
\hline $2-W$ & 1400.0 & 1957.0 & 1350.6 & 1868.4 & 1818.8 & 2125.4 & 1.04 & 1.05 & 1.08 & 0.92 \\
\hline 2-WO & 1750.0 & 1930.5 & 1344.4 & 1886.4 & 1835.1 & 2136.5 & 1.30 & 1.02 & 1.05 & 0.90 \\
\hline $3-W$ & 600.0 & 1554.9 & 1236.0 & 1681.7 & 1634.7 & 1880.9 & 0.49 & 0.92 & 0.95 & 0.83 \\
\hline 3.1-WO & 600.0 & 1612.1 & 1209.9 & 1663.2 & 1607.9 & 1850.5 & 0.50 & 0.97 & 1.00 & 0.87 \\
\hline 3.2-WO & 700.0 & 1701.9 & 1273.6 & 1747.3 & 1698.6 & 1947.4 & 0.55 & 0.97 & 1.00 & 0.87 \\
\hline $4-W$ & 900.0 & 1085.3 & 793.3 & 1065.6 & 1166.0 & 1207.1 & 1.13 & 1.02 & 0.93 & 0.90 \\
\hline 4-WO & 800.0 & 1184.2 & 827.9 & 1120.6 & 1208.0 & 1263.1 & 0.97 & 1.06 & 0.98 & 0.94 \\
\hline $5-\mathrm{W}$ & 750.0 & 1352.7 & 1087.0 & 1576.9 & 1586.9 & 1774.3 & 0.69 & 0.86 & 0.85 & 0.76 \\
\hline $5-W O$ & 1300.0 & 1543.7 & 1090.4 & 1587.9 & 1595.5 & 1786.1 & 1.19 & 0.97 & 0.97 & 0.86 \\
\hline $6-W$ & 950.0 & 1358.4 & 1096.8 & 1458.9 & 1443.0 & 1651.0 & 0.87 & 0.93 & 0.94 & 0.82 \\
\hline $7-W$ & 1025.0 & 1167.2 & 936.7 & 1214.3 & 1262.8 & 1369.6 & 1.09 & 0.96 & 0.92 & 0.85 \\
\hline 7-WO & 1100.0 & 1343.2 & 938.3 & 1216.5 & 1266.7 & 1371.8 & 1.17 & 1.10 & 1.06 & 0.98 \\
\hline $8-W$ & 900.0 & 1043.4 & 788.6 & 1011.0 & 1119.8 & 1131.5 & 1.14 & 1.03 & 0.93 & 0.92 \\
\hline \multirow[t]{4}{*}{ 8-WO } & 1000.0 & 1112.0 & 788.5 & 1011.6 & 1112.4 & 1133.1 & 1.27 & 1.10 & 1.00 & 0.98 \\
\hline & & & & & & Avg. all & 0.97 & 1.00 & 0.98 & 0.89 \\
\hline & & & & & & Avg. W & 0.95 & 0.97 & 0.95 & 0.86 \\
\hline & & & & & & Avg. WO & 0.98 & 1.02 & 1.01 & 0.91 \\
\hline
\end{tabular}

\section{Finite element analysis}

\subsection{Geometry, imperfections and mesh}

To verify the experimental results, four composite columns (1-WO, 3.2-WO, 4-WO, 5-WO) were analyzed using the finite element (FE) analysis software "ABAQUS". Twelve doubly symmetric quarter models (three of every column) were created (Fig. 10(a)) with the residual stresses. Four models had no geometrical imperfections and four more were created with the initial geometrical imperfections of the amplitude $B / 200$ [2], using the scaled linear buckling shapes from the linear buckling analysis performed previously (Fig. 10(b)). Four more models were created with the geometrical imperfections and the concrete protrusions of $0.3 \mathrm{~mm}$ above the steel edges to reflect the possible experimental inaccuracies.

Residual stresses were prescribed using the predefined fields function. The tensile residual stresses, compressive residual stresses and the corresponding areas of a single panel are shown in the Fig. 11 [25]. According to this model, the tensile stresses equal to the yield strength are induced in the welded column corner areas. The remaining area is then assigned with the compressive stress.

Additional models (one for every column) were created to evaluate the critical buckling stress of the columns. The latter models were created with the minor geometrical imperfections (amplitude $B / 1000$ ), as the experimental
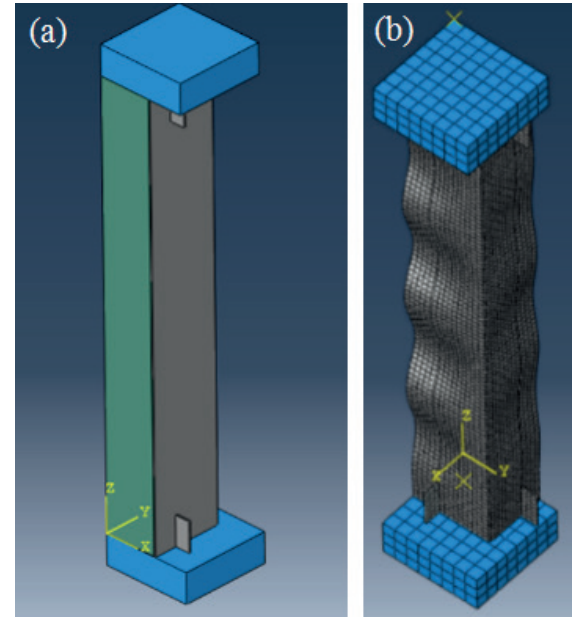

Fig. 10 Quarter column FE model (a) and scaled imperfection shape (b)

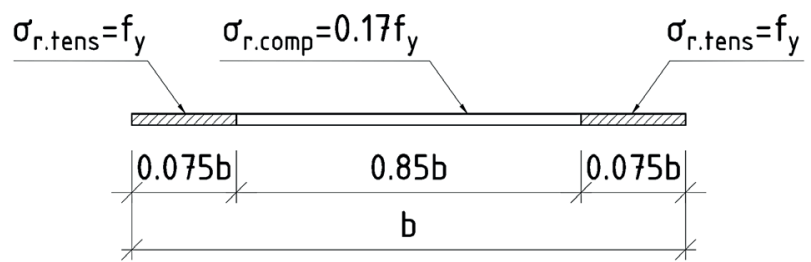

Fig. 11 Residual stress distribution in one steel panel

imperfections were not measured and thus are unknown. No residual stresses were prescribed, as the experimental residual stress values were not measured during the process of manufacturing. To evaluate the significance of the 
amplitude of the geometrical imperfections for the critical stress, columns 3-W, 3.1-WO, 3.2-WO were modelled with two different imperfection amplitudes: $B / 1000$ and $B / 200$.

Eight node solid mesh elements with reduced integration (C3D8R) were used for all the parts. The mesh size in the longitudinal direction was selected as $L / 100$ for the steel part and $L / 50$ for the concrete part. Along the cross-section contour the mesh size was assumed as the minimum of $B / 25$ and $H / 25$ for the steel part. The minimum of $B / 12.5$ and $H / 12.5$ was assumed for the concrete part [24].

\subsection{Material models}

An elastic-perfectly plastic stress-strain curve, yield strength of $370.85 \mathrm{MPa}$, Young's modulus of $210 \mathrm{GPa}$ and Poisson's ratio of 0.3 [1] was assumed. The Young's modulus values of the concrete were taken from the Table 1. The Poisson's ratio value of 0.2 [26] was assumed. The nonlinear stress-strain material model [26] was used to model the concrete. The average cubic strength values of the concrete from the Table 1 were converted to the cylinder strengths using Eq. 9 and used for the stress-strain curves.

The inelastic behavior of the concrete was modelled using the "Concrete Damaged Plasticity" (CDP) model in "ABAQUS" [27], which makes use of a non-associated plastic flow potential $G$, based on the Drucker-Prager hyperbolic function:

$$
G=\sqrt{\left(e f_{c t m} \tan \psi\right)^{2}+q^{2}}-p \tan \psi,
$$

where: $e$ is the flow potential eccentricity of the hyperbolic function, $\psi$ is the dilation angle, $q$ is the von Mises equivalent effective stress and $p$ is the hydrostatic pressure. The dilation angle value of $20^{\circ}$ [28] and the default eccentricity value of 0.1 [27] was used.

The CDP model also considers the initial equibiaxial compressive yield stress to initial uniaxial compressive yield stress ratio $f_{b 0} / f_{c 0}$ and the ratio of the second stress invariant on the tensile meridian to that on the compressive meridian $K_{c}$. The default values $f_{b 0} / f_{c 0}=1.16$ and $K_{c}=2 / 3$ [27] were used.

\subsection{Boundary conditions, contact and load}

The column was supported on the bottom plate and loaded via the loading plate. One reference point was created at the bottom of the bottom plate and one at the top of the loading plate. Those points were tied to the bottom and the top surfaces of those plates, respectively, using the kinematic coupling. The bottom reference point was supported to have zero degrees of freedom. The top reference point was prescribed a displacement load.

The contact interface between the steel profile and concrete in the normal direction was described as "hard". Thus, the penetration of one part into another was disallowed. The tangential contact was described as a frictional behavior with the coefficient of 0.57 [29] and a frictionless behavior for the WO type and W type columns, respectively. The contact between the plates and the column surfaces was also described as frictional.

\subsection{Results of the finite element analysis}

FE load-axial shortening curves are presented in Fig. 12 to Fig. 15. The summary of the FE ultimate loads and the comparison to the experimental and analytical results is presented in Table 6. The ultimate loads of the FE models corresponding best with the experimental ultimate loads are written in italic font. It was noticed that the geometrical imperfections reduced the ultimate strength by 3-5.5\% compared to the columns without the geometrical imperfections. The further decrease is observed when the concrete protrusion is introduced for the columns with the geometrical imperfections. The latter columns had a 6-9.5\% lower ultimate load compared to those with the residual stresses only. The ultimate strength of the columns 1-WO, 3.2-WO and 5-WO corresponded best with the FE models having the geometrical imperfections and concrete protrusion. The column 4-WO corresponded best with the FE model where only the residual stresses were present.

The numerical stiffness of the columns was found to be significantly higher than the experimental stiffness. The possible reasons for the relatively low experimental stiffness

Table 6 Comparison of the experimental, numerical and analytical ultimate loads

\begin{tabular}{|c|c|c|c|c|c|c|c|}
\hline $\begin{array}{l}\text { Column } \\
\text { specimen }\end{array}$ & $\begin{array}{c}N_{u, F E .1} \\
\text { (No geom. imp. } \\
\text { No conc. protrusion) }\end{array}$ & $\begin{array}{c}N_{u, F E .2} \\
\text { (Geom. imp. shape. } \\
\text { No conc. protrusion) }\end{array}$ & $\begin{array}{c}N_{u, F E .3} \\
\text { (Geom. imp. shape. } \\
\text { Conc. protrusion } 0.3 \mathrm{~mm} \text { ) }\end{array}$ & $\begin{array}{l}N_{u, e x} \\
(\mathrm{kN})\end{array}$ & $N_{u, \text { Liang }}(\mathrm{kN})$ & $N_{u, e x} / N_{u, F E}$ & $N_{u, \text { Liang }} / N_{u, F E}$ \\
\hline $1-W O$ & 1820.5 & 1741.0 & 1712.6 & 1682.6 & 1660.9 & 0.98 & 0.97 \\
\hline 4-WO & 1177.8 & 1140.0 & 1104.0 & 1184.2 & 1120.6 & 1.00 & 0.95 \\
\hline $5-W O$ & 1722.4 & 1664.9 & 1595.6 & 1543.7 & 1587.9 & 0.97 & 1.00 \\
\hline 3.2-WO & 1891.6 & 1786.6 & 1712.6 & 1701.9 & 1747.3 & 0.99 & 1.02 \\
\hline
\end{tabular}




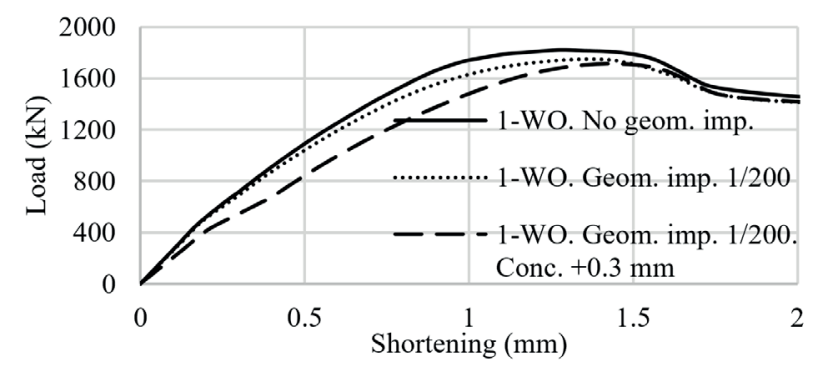

Fig. 12 Load-axial shortening of the column 1-WO

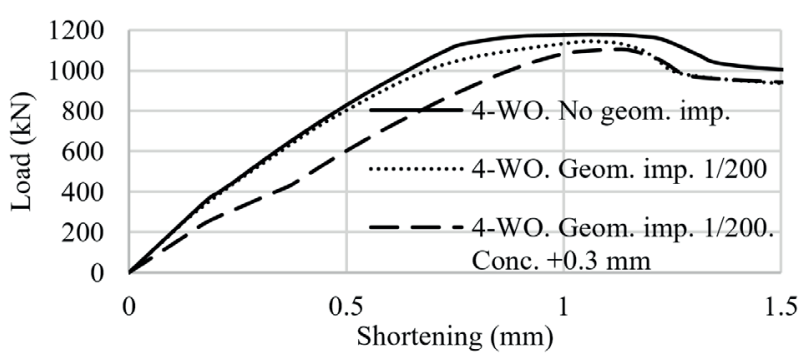

Fig. 13 Load-axial shortening of the column 4-WO

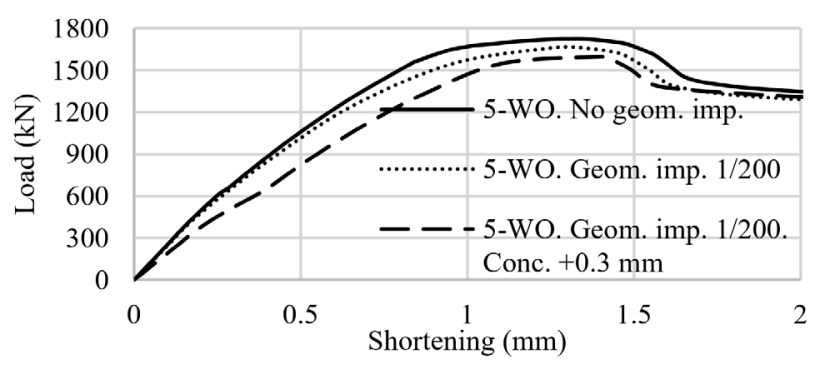

Fig. 14 Load-axial shortening of the column 5-WO

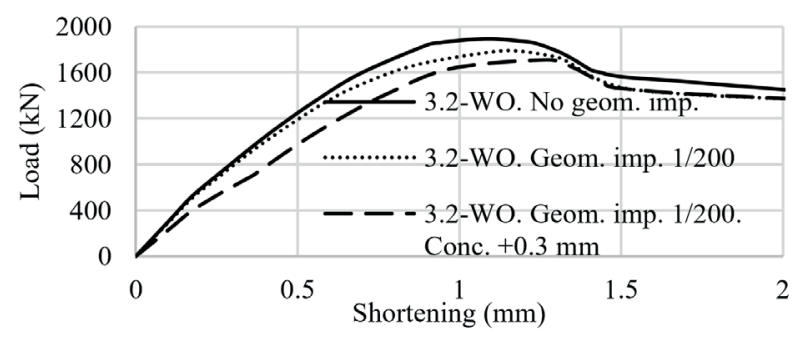

Fig. 15 Load-axial shortening of the column 3.2-WO

were described in the previous sections. The numerical analysis yields the exact shortening results, as the shortening between the two ends of the column is measured.

Ultimate load stresses of the column 1-WO are presented in Fig. 16(a). The contact pressure on the protruded concrete surface right before the steel profile was loaded is presented in Fig. 16(b). At that moment, the stresses in the concrete have reached up to $20 \mathrm{MPa}$. Because of this type of initial loading, the concrete stresses may have already decreased significantly at the ultimate load of the column, as the strains corresponding to the ultimate stress of the concrete can be exceeded. In this case, the column may not attain the predicted full elastic stiffness and the ultimate strength may be lower than predicted. It is obvious that the ultimate strength and the shape of the load-axial shortening curve depends on the various factors: geometrical imperfection shape, level of residual stresses, protrusions of the concrete.

Additional FE models were analyzed to obtain the critical stress values. The results of the two webs of every column are presented in Table 7, where $b$ and $h$ are the inner width and height, respectively; $\sigma_{1 c, b, F E}$ and $\sigma_{1 c, h, F E}$ are the corresponding numerical critical stresses; $\sigma_{1 c, b, L}$ and $\sigma_{1 c, h, L}$ are the corresponding analytical critical stresses obtained from Eq. 2. The FE and analytical critical buckling values are different. The main reason is the different amplitudes of the initial geometrical imperfections. The amplitudes of $0.1 t$ were selected in the research of Liang and Uy [7], while $B / 1000$ amplitudes were selected in this part of the research.
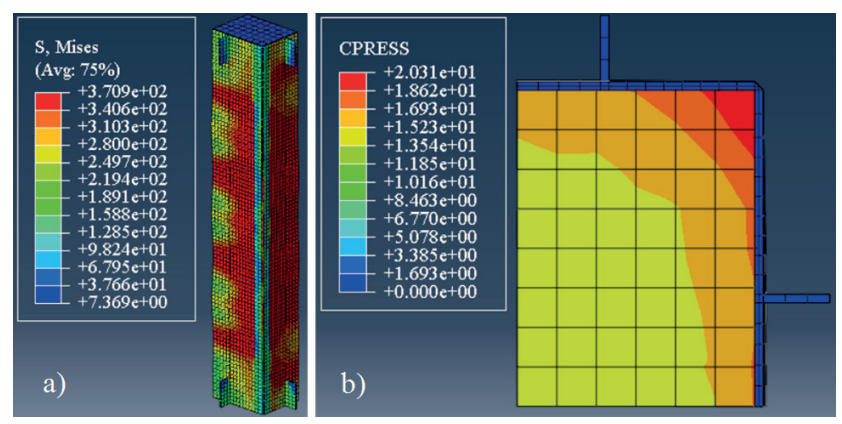

Fig. 16 Ultimate load stresses (a) and contact pressure in the concrete protrusion of the column 1-WO right before the steel was loaded (b)

Table 7 Critical stress values of the FE models

\begin{tabular}{lcccccc}
\hline Specimen & $\mathrm{b}$ & $\mathrm{h}$ & $\sigma_{1 c, b, F E}$ & $\sigma_{1 c, b, L}$ & $\sigma_{1 c, h, F E}$ & $\sigma_{1 c, h, L}$ \\
\hline 1-W & 238.1 & 178.6 & 185.0 & 150.4 & 262.8 & 199.1 \\
1-WO & 238.7 & 178.7 & 186.2 & 155.8 & 267.0 & 201.5 \\
2-W & 236.8 & 237.3 & 192.0 & 157.9 & 191.8 & 157.7 \\
2-WO & 237.5 & 237.2 & 191.9 & 154.5 & 192.2 & 154.9 \\
3-W & 197.8 & 197.8 & 236.8 & 187.5 & 236.8 & 187.5 \\
3.1-WO & 198.0 & 198.0 & 237.3 & 184.0 & 237.3 & 184.0 \\
3.2-WO & 198.8 & 199.3 & 237.2 & 187.2 & 236.8 & 186.9 \\
4-W & 178.7 & 117.0 & 267.2 & 202.6 & 326.8 & 226.7 \\
4-WO & 178.6 & 119.1 & 264.1 & 201.0 & 323.5 & 225.9 \\
5-W & 217.7 & 157.4 & 205.7 & 171.2 & 278.2 & 211.7 \\
5-WO & 218.7 & 158.4 & 206.1 & 170.1 & 277.0 & 211.0 \\
6-W & 178.3 & 179.0 & 262.3 & 196.4 & 261.9 & 195.9 \\
7-W & 158.9 & 158.9 & 283.9 & 210.9 & 283.9 & 210.9 \\
7-WO & 158.6 & 159.1 & 280.4 & 211.3 & 280.0 & 211.0 \\
8-W & 138.8 & 138.8 & 294.6 & 219.9 & 294.6 & 219.9 \\
8-WO & 139.4 & 139.7 & 299.4 & 219.2 & 298.8 & 219.1 \\
\hline
\end{tabular}




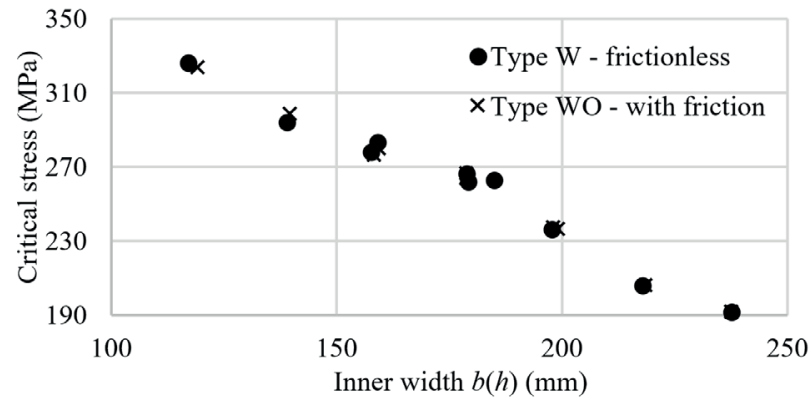

Fig. 17 Critical stress-inner width (height) of the column dependency

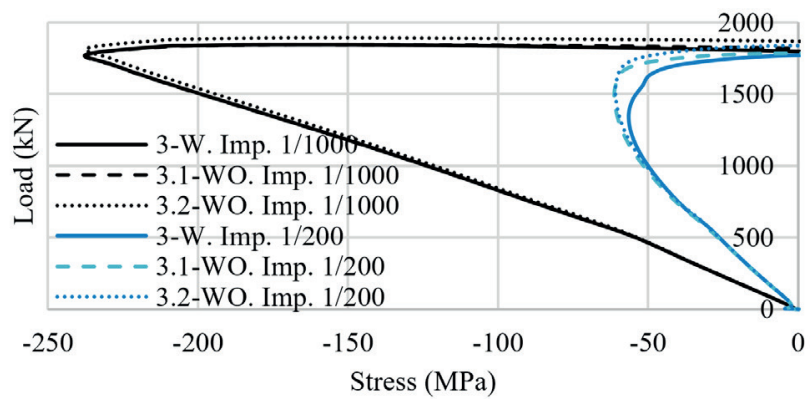

Fig. 18 Numerical stress-load curves of the columns

The FE critical stress results are also presented in Fig. 17. It can be seen that the critical stress-inner width (or height) dependency is linear. The difference between the $\mathrm{W}$ and WO type of columns was negligible. However, the WO type of columns were modelled using a frictional contact. The cohesive stiffness, damage initiation and evolution parameters were not measured during the experimental campaign. Thus, the exact cohesive behavior could not be set up in the numerical study. It could be expected that the cohesion would increase the critical stress of the FE models.

The stress development of the columns 3-W, 3.1-WO and 3.2-WO is presented in Fig. 18. It was found that the critical stress and the initial slope of the stress-load curve depends strongly on the geometrical imperfection amplitude. The models with a low imperfection amplitude of $B / 1000$ have shown a late and sharp buckling. When the buckling started, the columns were close to the ultimate strength. However, when the imperfection amplitude was increased to $B / 200$, the critical stress was 4-5 times lower. The onset and development of the buckling wave was softer and more gradual. When the buckling started, the latter columns have reached $60-70 \%$ of the ultimate strength.

\section{References}

[1] CEN "EN 1993-1-1 Eurocode 3: Design of steel structures - Part 1-1: General rules and rules for buildings", European Committee for Standardization, Brussels, Belgium, 2005.

\section{Conclusions}

This paper presents an experimental investigation of the thin-walled square and rectangular composite steel-concrete columns. Most cross-sections of the columns had at least two specimens: with and without the bond between the steel and concrete. The analytical calculations and FE analyses were carried out and compared to the experimental results. The main conclusions of this research are:

- Experimental tests have shown that the columns without the film inside had an up to +0.24 (series 7 ) or $+47 \%$ (series 5 ) higher relative effective area factor $A_{\text {eff }} / A$ than the corresponding columns with the film. Therefore, it is very important to ensure the good bond conditions.

- The average reduction of the effective cross-sectional area $A_{\text {eff }}$ for the columns having a poor bond was $12 \%$, compared to the columns having a good bond.

- The best agreement between the experimental and analytical ultimate loads of the steel-concrete columns was obtained using the analytical method of Liang. The extreme values varied from the underprediction of $10 \%$ to the overprediction of $14 \%$, which could be critical.

- The critical buckling stress of the columns with the small geometrical imperfections decreased linearly while increasing the width of the cross-sections. However, critical buckling stresses were found to be very sensitive for the amplitude of geometrical imperfections. The columns with the higher amplitudes have shown a softer and gradual buckling behavior.

- FE ultimate load predictions depend on the initial imperfections. It was found that the geometrical imperfections reduced the ultimate strength by 3-5.5\% compared to the models without the geometrical imperfections. Even the slight protrusions of the concrete above the steel profile may reduce the ultimate strength further. Additional 1.5-4\% decrease of the ultimate load was observed for the specimens having this kind of protrusion and geometrical imperfections.

[2] CEN "EN 1993-1-5 Eurocode 3: Design of steel structures Part 1-5: Plated structural elements", European Committee for Standardization, Brussels, Belgium, 2005. 
[3] CEN "EN 1994-1-1 Eurocode 4: Design of composite steel and concrete structures - Part 1-1: General rules and rules for buildings", European Committee for Standardization, Brussels, Belgium, 2004.

[4] Faxén, O. H. "Die Knickfestigkeit rechteckiger Platten" (The kink resistance of rectangular panels), Zeitschrift für Angewandte Mathematik und Mechanik, 15(5), pp. 268-277, 1935. (in German) https://doi.org/10.1002/zamm.19350150505

[5] Uy, B., Bradford, M. A. "Elastic local buckling of steel plates in composite steel-concrete members", Engineering Structures, 18(3), pp. 193-200, 1996.

https://doi.org/10.1016/0141-0296(95)00143-3

[6] Timoshenko, S. P., Gere, J. M. "Theory of elastic stability", 2nd ed., Dover Publications, Mineola, NY, USA, 2009.

[7] Liang, Q. Q., Uy, B. "Theoretical study on the post-local buckling of steel plates in concrete-filled box columns", Computers and Structures, 75(5), pp. 479-490, 2000. https://doi.org/10.1016/S0045-7949(99)00104-2

[8] Song, Y., Li, J., Chen, Y. "Local and post-local buckling of normal/high strength steel sections with concrete infill", Thin-Walled Structures, 138, pp. 155-169, 2019. https://doi.org/10.1016/j.tws.2019.02.004

[9] Uy, B. "Strength of Concrete Filled Steel Box Columns Incorporating Local Buckling", Journal of Structural Engineering, 126(3), pp. 341-352, 2000 https://doi.org/10.1061/(ASCE)0733-9445(2000)126:3(341)

[10] Uy, B. "Local and Postlocal Buckling of Fabricated Steel and Composite Cross Sections", Journal of Structural Engineering, 127(6), pp. 666-677, 2001. https://doi.org/10.1061/(ASCE)0733-9445(2001)127:6(666)

[11] Liang, Q. Q., Uy, B., Liew, J. Y. R. "Local buckling of steel plates in concrete-filled thin-walled steel tubular beam-columns", Journal of Constructional Steel Research, 63(3), pp. 396-405, 2007. https://doi.org/10.1016/j.jcsr.2006.05.004

[12] Hu, H.-T., Huang, C.-S., Wu, M.-H., Wu, Y.-M. "Nonlinear Analysis of Axially Loaded Concrete-Filled Tube Columns with Confinement Effect", Journal of Structural Engineering, 129(10), pp. 1322-1329, 2003.

https://doi.org/10.1061/(ASCE)0733-9445(2003)129:10(1322)

[13] Han, L.-H., Zhao, X.-L., Tao, Z. "Tests and mechanics model for concrete-filled SHS stub columns, columns and beam-columns", Steel and Composite Structures, 1(1), pp. 51-74, 2001. https://doi.org/10.12989/scs.2001.1.1.051

[14] Han, L.-H. "Flexural behaviour of concrete-filled steel tubes", Journal of Constructional Steel Research, 60(2), pp. 313-337, 2004. https://doi.org/10.1016/j.jcsr.2003.08.009

[15] CEN "EN 12390-3 Testing hardened concrete - Part 3: Compressive strength of test specimens", European Committee for Standardization, Brussels, Belgium, 2019.
[16] CEN "EN 12390-13 Testing hardened concrete - Part 13: Determination of secant modulus of elasticity in compression", CEN, Brussels, Belgium, 2013.

[17] CEN "EN ISO 6892-1 Metallic materials - Part 1: Method of test at room temperature", European Committee for Standardization, Brussels, Belgium, 2019.

[18] Bulson, P. S. "The stability of flat plates", Chatto and Windus, London, United Kingdom, 1970.

[19] Liang, Q. Q. "Performance-based optimization of structures: Theory and applications", Spon Press, Abingdon, United Kingdom, 2005,

[20] Bradford, M. A., Bridge, R. Q., Hancock, G. J., Rotter, J. M., Trahair, N. S. "Australian Limit State Design Rules for the Stability of Steel Structures", In: International Conference on Steel and Aluminium Structures, Cardiff, United Kingdom, 1987, pp. 209-216.

[21] Ge, H. B., Usami, T. "Strength analysis of concrete-filled thin-walled steel box columns", Journal of Constructional Steel Research, 30(3), pp. 259-281, 1994. https://doi.org/10.1016/0143-974X(94)90003-5

[22] Duarte, A. P. C., Silva, B. A., Silvestre, N., de Brito, J., Júlio, E., Castro, J. M. "Experimental study on short rubberized concrete-filled steel tubes under cyclic loading", Composite Structures, 136, pp. 394-404, 2016.

https://doi.org/10.1016/j.compstruct.2015.10.015

[23] Ellobody, E., Young, B. "Nonlinear analysis of concrete-filled steel SHS and RHS columns", Thin-Walled Structures, 44(8), pp. 919930, 2006.

https://doi.org/10.1016/j.tws.2006.07.005

[24] Duarte, A. P. C., Silva, B. A., Silvestre, N., de Brito, J., Júlio, E., Castro, J. M. "Finite element modelling of short steel tubes filled with rubberized concrete", Composite Structures, 150, pp. 28-40, 2016. https://doi.org/10.1016/j.compstruct.2016.04.048

[25] Uy, B. "Local and post-local buckling of concrete filled steel welded box columns", Journal of Constructional Steel Research, 47(1-2), pp. $47-72,1998$. https://doi.org/10.1016/S0143-974X(98)80102-8

[26] CEN "EN 1992-1-1 Eurocode 2: Design of concrete structures - Part 1-1: General rules and rules for buildings", Committee for Standardization, Brussels, Belgium, 2004.

[27] Dassault Systemes "ABAQUS 6.14 Analysis User's Guide", Providence, Rhode Island, USA, [online] Available at: http://ivt-abaqusdoc.ivt.ntnu.no:2080/v6.14/books/usb/default.htm

[28] Ellobody, E., Young, B., Lam, D. "Behaviour of normal and high strength concrete-filled compact steel tube circular stub columns", Journal of Constructional Steel Research, 62(7), pp. 706-715, 2006. https://doi.org/10.1016/j.jcsr.2005.11.002

[29] Rabbat, B. G., Russell, H. G. "Friction Coefficient of Steel on Concrete or Grout", Journal of Structural Engineering, 111(3), pp. 505-515, 1985.

https://doi.org/10.1061/(ASCE)0733-9445(1985)111:3(505) 